\title{
Research and Practice on Media Assistive High Efficient Autonomous Learning Mode
}

\author{
Liu Lei
}

Department of Computer Science and Technology Dalian Neusoft Institute of Information Dalian, China

\begin{abstract}
Different from the traditional sense of self-study, this paper takes a new understanding of the definition and concept of autonomic learning. It brings forward the self-study mode called "target, design, implementation, and test", and it raises the idea of establishing the platform of multimedia assistive autonomic learning so as to help the learners to fulfill a more efficient and motivating learning process. The case research is based on the intramural educating and learning website, and the evaluation is based on a comprehensive scoring system.
\end{abstract}

Index Terms: autonomous learning; high efficient learning; remote education; self-study platform

(C) 2011 Published by MECS Publisher. Selection and/or peer review under responsibility of the International Conference on E-Business System and Education Technology

\section{Innovation of understanding on autonomous learning}

Autonomous learning is a process to form the full-dimensional thinking of knowledge with the learners being leading actors, and it is essentially differs from the mode of face to face teaching. To study independently the learners have to grasp the lore by the thinking processes of recalling, associating, comparing and judging, etc. Therefore, it stimulates the learners' active thinking, and makes the learners to have a solid and profound acquisition of the knowledge.

Learning takes many forms, in which lectures and self-study supplement each other. Lectures without selfstudy often leads to an unstable grasp of knowledge, and things learnt by lectures will disappear after a period of time. The result of self-study without lectures is bad too, and it is often caught in "blind" for the lack of relevant guidance.

Should both commentators and listeners be involved in the process of learning? If the teacher is a multimedia teaching equipment, will the effect be better or worse than teachers?

Traditional teaching mode-teaching person to person has the following characteristics.

First, the limitation of communication is inevitable [1]. Teachers and students need to communicate by language, and the knowledge transfer is limited by teachers' ability of language competence. In an interactive process, both sides need considerable time to clear the meaning expressed. Teachers often get to know whether

Corresponding author:

E-mail address: liulei@neusoft.edu.cn 
the students have grasped the knowledge. They come to a conclusion by many methods including observation, testing and questioning, in order to decide whether to continue or not. Teaching in class, teachers often focus on the majority while neglect of the needs of minorities. Secondly, the emotions become a major factor that influences the teaching effect. Students' emotions such like trust, empathy and emotional dependence on teachers will affect the understanding and acceptance of knowledge. Some students can not adapt to classroom psychologically, and this directly affects their learning outcomes in schools. Thirdly, since many people are involved in the teaching process, teachers are responsible for the organization and management, and the operation of class-controlling will also affect the learning.

On the contrary, self-study mode is fit for most people, because it removes the communication barriers from learning process, and the emotional impact is eliminated also. Therefore self-study is a relaxed and more effective way of learning. If add the multimedia assistive learning platform to the process, it will be a faster and more effective learning process [2].

\section{Self-study breakthrough}

The limitations of self-study include the following points.

First, the learner lacks of guidance. Learning a course, a profession, or to grasp a skill can't be realized by reading one or two books. The individual learner without predecessors' guidance can't hold the orientation in full view, and to control the rate of study progress, or collecting materials will all become difficult.

Second, a single learner lacks of complementary lore [3]. When encounter problems in the learning progress, it is hard for the learner to conquer the difficulty without knowing the relevant knowledge, and it is hard to understand some theoretical issues without the bedding of some relevant courses.

Thirdly, learners lack of the full-scale of knowledge scopes. The following questions will all be difficult to answer. Learning a profession, where should I start with? What should be learned as the next topic? Which quality could I acquire after the learning? Which course should be the next one? Which issues should be focused on? What are the preparations I am making for? All those are the questions need to be answered.

The self-study mode of "target, design, implementation, and test" is the solution to break the limitations listed above, and can also realize high efficient learning.

What does "target" mean? The most important issue for a learner is to have clear purpose, and to setup a target for the study, which ultimately determines the outcome. Before starting learning, the learner should be clearly aware of what knowledge or skills will be acquired, what qualities or abilities should be trained during the learning progress, what kinds of issues can be solved by the courses, what kinds of work is the courses preparing for, and which aspects should be in-depth studied in the process.

For example, the course of "C Programming Language" is one of the fundamental courses for professional direction of computer science, and it is bedding for the follow-up courses such as Data Structure, Software Engineering, and Java Programming [4]. Its location in the curriculum structure can be found in the fish bone diagram. The fish bone diagram is drawn as shown in Fig 1. 


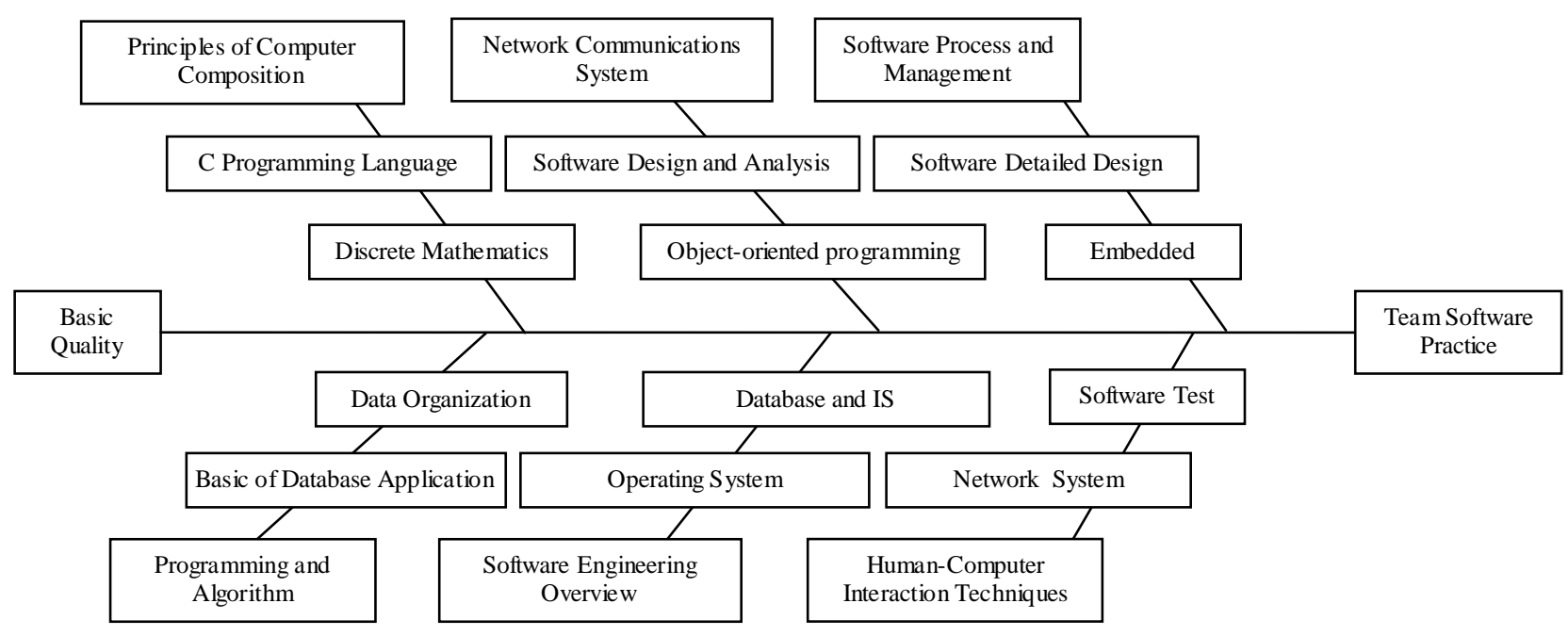

Figure1 Fishbone of Software Engineering Courses

All these curriculum structure designs need to be explicitly given by the subject experts. Therefore, in the selfstudy platform every profession and every course should give introduction, which clearly introduce the knowledge system, including the role and position of the course in the professional learning, the history and practical way of the course, and the key points and difficulties of the course.

What does "design" mean? The course won't achieve good educational results if explained dully or generalized regardless of the object. The ideal way of teaching is allowing the learners to select suitable content to study and control the rate of progress by themselves. Thus, the autonomous learning assistive platform should provide different levels of explanation to the learners for their study [5]. According to their own intellect, the learners can select suitable degree for them to learn in primary explanation, secondary explanation, or advanced explanation.

What does "implementation" mean? Implementation refers to the learning process. All kinds of learning methods, such as the review, consolidation, question, association and comparison should be combined together, in order to achieve a multiplier effect. To design and establish the autonomous learning platform, different kinds of learning methods should be provided, such as listening, speaking, reading and writing for language study, logic guess and calculation exercises for mathematics study, etc. Thus the platform can provide reasonable and efficient methods to the learners.

What does "test" mean? Test is to determine whether the desired objectives are achieved by evaluating the learner's knowledge, skills, and qualities. The purpose of test is to check the learning effect. Test can be combined with many aspects, through which we can find out many facts. For example, whether the key points of knowledge have been grasped; whether the minor points of knowledge have been known; whether the mastered skills can accomplish the relevant tasks? And the way of tests can be diversiform, such like subject test, independent projects, practical activities, exchange visits, comparative mutual learning and so on.

The self-study mode "target, design, implementation, and test" incorporates today's latest achievements in the reform of teaching, providing the most convenient conditions to the learners. But if we want to fully apply the autonomous learning mode, there could be higher demands for media assistive learning platform 


\section{The concept of autonomous learning platform}

\section{1 Knowledge Becomes Into System}

The curriculum structure of the courses for the autonomous learning platform should not be in a loose mode as in the past, but be linked judiciously together. The curriculum schedule should be organized according to the discipline, and be described in detail for the learners' awareness. The curriculum system should be made with integral plan, in which all courses are aimed at one ultimate target. The overall description of the curriculum should be composed with the core curriculum, the knowledge system structure, the aim of curriculum, so that the learners can have a global awareness of the curriculum, and accordingly carry out self-study.

\section{2 Expert System of Teaching}

In essence, the platform of autonomous learning should be a teaching system. It should be able to carry out the teaching process in plan, and step by step to develop the learner's cognitive level, promote the completeness of knowledge system. It makes various teaching methods to be used reasonably, including playing lectures videos, text explanations, graphic illustration, cartoon presentation, live-action show, reading comprehension, and other traditional methods as well as the modern methods of sand table exercise, scenario simulation and so on.

\section{3 Integration of Learning, Practice and Test}

The platform of autonomous learning should provide a full combination of teaching functions including learning, practice and test to the learners. What's more, it should summarize and assess the learning outcomes with scores. Learning, practice and test are closely connected. Learners should be provided with a large number of exercises, which need to be stored in a large training database. The graders and scoring functions are needed to assess the learning outcomes, and artificial intelligence scoring system is needed to judge the subjective answers.

\section{4 Creations and Display}

After mastery of certain knowledge and skills the learners can complete certain tasks to make the value of knowledge realized. Therefore learners should be provided spaces to display their academic works. The outcome of self-study is embodied through the application and re-creation of knowledge.

\section{5 Communication, Question \& Answer}

With the support of terminal units such as computers, cell phones and so on, self-learners can communicate at any moment. Self-learners can acquire tutorship by asking questions to tutors. Discussions can be open out among learners, and topics can be attended by all means whenever they are placed online or into instant messaging system, e-mail, message boards or other forms.

\section{6 Protection of Intellectual Property}

The resources of autonomous learning platform are invested with a lot of money and manpower, so it is not allowed to be easily stolen, or freely occupied. When opened to the public, its copy rights should be protected, and we should prevent illegal piracy, possession and dissemination. Therefore various measures should be taken 
to protect the security of the network platform, and make the necessary prevention. Comprehensive security measures are necessary, and they should be designed at the beginning of the platform build up. It will be more effective to make security at the first stage than make it up at the later stage. The recommended technical measures are as follows.

1) Multiple protection and encryption technology ought to be used.

2) Web content (text, picture) should be really protected to prevent being copied.

3) Encryption and decryption of bulk files should be achieved.

4) Digital watermarking technology should be applied to protect copyright of the website pictures.

\section{Implementation}

The online self-study platform for students has been running for years in our school, by which students can study independently in their spare time, and to fulfill the courses will receive the credits. The innovation of teaching theory and practice has been proved to be effective, and the perfect performance can be observed by scoring system. We have fully developed and tested the self-study mode to give lessons of the most advanced educational strategy, which is synoptically called "target, design, implementation, and test". With the development of network technology, the terminal equipments, such as computers, mobile phones, laptops and so on widely used, people can learn knowledge everywhere at any moment. The multimedia assistive self-study platform will surely become the universal popularity.

\section{References}

[1] L. Dee Fink and K. Li, "A self-directed guide to designing courses for significant learning:designing courses that promote significant learning", CSSCI. J. Fudan Education Forum. Shanghai:China, vol. 6, No 1,pp. 72-80, Jan 2008.(in Chinese)

[2] Y. Liu, J. J. Hou and H. J. Chen, "Experimental teaching center construction and practice of curriculum design”, CSSCI.J.China University Teaching. Beijing:China, vol 4, pp 75-77, April 2008. (in Chinese)

[3] Y. F. Song, "Case study teaching in the design of self-guidance", J.Journal of Shanxi Normal University.Shanxi:China, vol 36, pp 172-174, Nov 2009. (in Chinese)

[4] S. H. Zhang, H. P. Han and Z. R. Yin, "Self-learning: the exchange of teaching mode of innovative educational value", CSSCI.J.China University Teaching. Beijing:China, vol 10, pp 84-86. Dec 2009. (in Chinese)

[5] X. F. Liu and N. Li, "Discussion on the self-learning thought on mencius",J.Adault Education. Haerbin:China, vol 280. May 2010. (in Chinese) 